\title{
Long-running traditions of racial exclusionism: is there evidence of historical continuity in local support for extreme right parties in England and Wales?
}

\author{
Juta Kawalerowicz
}

\author{
Journal Article
}

\section{Tweet}

N.B.: When citing this work, cite the original article.

Original Publication:

Kawalerowicz Juta, Long-running traditions of racial exclusionism: is there evidence of historical continuity in local support for extreme right parties in England and Wales?, Party Politics. 2017.

Copyright: SAGE Publications (UK and US)

http://www.uk.sagepub.com/home.nav

Postprint available at: Linköping University Electronic Press

http://urn.kb.se/resolve?urn=urn:nbn:se:liu:diva-136744

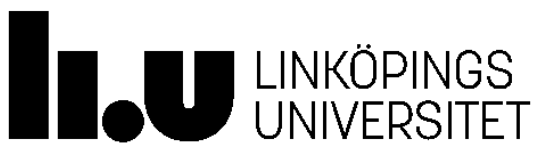


Long-running traditions of racial exclusionism: is there evidence of historical continuity in local support for extreme right parties in England and Wales?

Some regions of the United Kingdom present more fertile grounds for consecutive incarnations of extreme right parties than others. In a study by Goodwin, Ford and Cutts the authors found evidence of the legacy effect, where an earlier cycle of activism by the National Front (NF), an extreme right political party active in the 1970s, emerged as a strong and significant predictor of membership in the British National Party (BNP) three decades later. While their study speaks to the supply-side arguments for extreme right success (organizational continuity and local cultural traditions in particular), here we examine whether a similar legacy effect can be observed with respect to demand for extreme right politics. As we are going to show there is some overlap between the share of votes cast for the NF and the BNP, yet there are a number of constituencies that do not adhere to this pattern. We conclude that while the supply-side legacy effect is not ruled out, the legacy effect hypothesis does not find support for demand-side explanation of extreme right support.

In his book titled New British Fascism, Matthew Goodwin argues that support for the BNP is built on a legacy of earlier extreme right groups such as the National Front (2011). This toxic lineage is one of the reasons why the BNP enjoyed only a limited success in comparison with similar parties in Europe and why it has been difficult for the UK Independence Party to break though ${ }^{1}$ (Goodwin 2011, Ford and Goodwin 2014). In a contextual analysis of the leaked BNP membership list published by this journal Goodwin, Ford and Cutts show that historical party activism in the 1970s predicts BNP membership in the modern era (2013). While Goodwin and colleagues look at supply-side explanations of extreme right success, here we focus on electoral demand for extreme right politics and its alleged continuity in space and time. As we are going to show, although there is a weak positive correlation between electoral

\footnotetext{
${ }^{1}$ In some cases this connection proves to be less problematic. According to Duncan Morrow the Freedom Party of Austria has never fully rejected the historical legacy of the far right, engaging in conscious 'flirtations with former Nazis' and serving as 'a political vehicle for integrating former Nazis' while gaining wider political acceptance (2000). British context is different because British national identity is largely build around the struggle against fascism and Nazism (Goodwin 2011). Hence, any links with neo-Nazi movement prove to be particularly toxic.
} 
support for the NF and the BNP, it disappears once more exact measures of electoral support are introduced. We compare regression results obtained with binary measures of electoral support (i.e. whether there was a candidate running or not) and measures obtained with areal interpolation and show that they lead to different conclusions. Goodwin and colleagues examine legacy effect with regards to party activism at the local authority level while we look at electoral support within a smaller geographical level of Westminster constituencies. It is worth emphasizing that party activism and voting represent two different types of support, where the former does not always neatly translate into the latter ${ }^{2}$, hence showing that contemporary voting is not affected by historical vote does not rule out a corresponding effect with regards to party activism. This study contributes to the literature on the extreme right in the United Kingdom by examining evidence for a demand-side legacy effect, providing an empirical application of a novel areal interpolation method and showing that demand-side legacy effect disappears once we introduce more exact measures of electoral support.

In recent years we have seen a revival of the legacy hypothesis of extreme right support in the United Kingdom which asserts that contemporary extreme right parties are drawing on the legacy of activism from an earlier, more violent era (Goodwin, 2011). As reported by Goodwin and colleagues this pattern has been observed in case of Vlaams Block in Antwerp and the Austrian Freedom Party in Carinthia, but also in Britain (Husbands 1983, Goodwin, Ford, and Cutts 2013, Mudde 2007). Examining the BNP membership, Goodwin suggested that 'One possible explanation for the geographical distribution of members is that regions where membership is strongest have long been targeted by the extreme right, and have tended to provide disproportionately high levels of support for these parties.' This pattern is most visible in parts of Midlands where the BNP is thought to be benefiting from earlier campaigns of the extreme right, which is manifested by a spatial overlap between areas known to support the extreme right in the 1970s and more recent BNP's strongholds. This line of argument is developed further by Goodwin, Ford and Cutts who place the legacy effect within a theoretical framework of supply and demand cantered explanations for emergence and success of extreme right parties. This framework can be traced to

\footnotetext{
${ }^{2}$ For instance, Biggs and Knauss (2012) observed that BNP membership is only weakly ( $\left.\mathrm{r}=0.46\right)$ correlated with BNP vote in constituency.
} 
Roger Eatwell (2003) who argued that academics focus mostly on explaining the demand for such parties, finding that it is affected by factors such as levels of education or proximity to ethnic minorities. Yet, in doing so they often overlook the question of supply: how such parties find their place in the political space and how they organize and prevail in a given area. Goodwin and colleagues engage with the supply-side argument and show that when a binary variable for a legacy effect is introduced into their model, earlier presence of the NF is a significant predictor of contemporary BNP membership. The authors report that 'membership of the modern BNP is significantly elevated (17 per cent higher) in authorities where the old NF was active in the 1970s, holding other socio-economic and supply-side variables constant' (2013). Additional support is provided by survey studies that show support for the NF came predominantly from young, skilled men with working class background ${ }^{3}$ (Whitley 1979; Harrop, England, and Husbands 1980) while the BNP attracted older, less educated working-class men (Ford and Goodwin 2010). This opens a possibility that supporters were partly recruited from the matured 'old guard' of the NF. Indeed, it has been shown that the BNP relied on existing networks of extreme right supporters and many activists, including the leadership, were previously engaged with the NF. What could be the reason for the alleged long-running support in some regions? Is there really something distinctive about them, possibly an indication that extreme right organizations have operated in these regions throughout the last decades?

Goodwin, Ford and Cutts argue that aside from a possibility that both parties attracted same people, there is another interpretation of the supply-side legacy effect. It is plausible that earlier cycles of activism had a lasting effect on local cultural traditions, creating a climate of racial exclusionism that in later years helped the BNP to emerge and establish in the area. This thinking is influenced by the work of Christopher Husbands and his Racial Exclusionism and the City (1983). In an attempt to explain the rise of the NF in the 1970s, Husbands provides detailed local histories of party strongholds and hypothesizes that areas supporting the NF were a special class of 'demoralized' working-class neighbourhoods with a long-running tradition of ethnic exclusionism developed independently of the economic factors. According to

\footnotetext{
${ }^{3}$ The fact that NF is the only other episode in British electoral history when an extreme right party gained noticeable support makes it a good candidate for a party representing the legacy of extreme right activism from an earlier era.
} 
Husbands, parts of East End, Enfield, Lewisham, Slough, Bradford, Lancashire, Leicestershire and Wolverhampton experienced a 'common decline or degradation not merely of their economic circumstance but also their local culture' and as a result at various times they had been successfully targeted by a wide range of extreme right fractions from the anti-Semitic British Brothers' League, Oswald's British Union of Fascists and Socialists, Union Movement, British National Party, British Campaign to Stop immigration to the Anti-Immigration Society and the National Front ${ }^{4}$. This raises the question whether extreme right organization ever stopped contributing to a local cultural legacy of intolerance in these regions.

As mentioned previously, supply-side explanations look at political opportunity structure and organizational factors. We have described the argument behind the supply-side legacy effect found by Goodwin and colleagues but does a similar legacy effect exist with respect to demand for extreme right parties? These two are closely linked: without organizations and activists voters could never realize their electoral preferences. On the other hand, changing preferences, beliefs and attitudes among voters lead to opening of new organizational units. Are there localities where extreme right parties did well historically and where they still receive an electoral boost 30 years later? Commenting on the distribution of support for historical and contemporary extreme right parties in Britain, Ford and Goodwin note that there seems to be 'a significant shift in the geographical distribution of extreme right support.' Historical support for the NF was concentred in West Midlands and London, yet the BNP is not strong in these areas. Rather, Ford and Goodwin observe, bases of support seem to move northwards to Yorkshire and Lancashire. To address this problem rigorously, one would need to show how NF support is associated with BNP support where both are calculated within the same set of electoral boundaries. This is not easy because electoral boundaries have undergone multiple revisions between 1970s and 2000s and old constituencies do not have a straightforward mapping into new electoral boundaries. This problem can be addressed either by using coarse measures such as

\footnotetext{
${ }^{4}$ The historical analysis and rich accounts provided by Husbands often go as far back as the middle of $19^{\text {th }}$ century. The author identifies the development of the Labour movement around the time of 1906 General Elections as a decisive moment when autonomous working-class politics have been born and local political traditions established.
} 
binary variables (which are coded 1 if new constituency shares some area with old constituency and 0 otherwise) or by trying to estimate more exact levels of support with the use of lookup files (which are not always available). In contrast to Goodwin et al. who use three supply-side variables (BNP winning council seats in the local authority, BNP establishing branches in the local authority, dummy for wards located within parliamentary constituencies where the NF stood in the past) we focus exclusively on the legacy effect variable. We expect that the NF vote would predict contemporary electoral performance of the BNP, even after introducing controls for socio-economic characteristics of constituencies (Hypothesis 1).

\section{DATA AND METHOD}

The dependent variable is the BNP electoral performance in England in Wales measured as a per cent of vote for the BNP in the 2005 general elections recorded in each of the 569 parliamentary constituencies in England and Wales ${ }^{5}$. Electoral data comes from the British Parliamentary Constituency Database 1992-2005 compiled by Pippa Norris and is combined with socio-economic controls for the share of residents in routine and semi-routine occupations (NS-SEC class 5), degree qualifications, nonwhite residents, house ownership, council housing, population density and a binary variable for Wales. All control variables are taken from the 2001 Census. Detailed electoral data from the 1970s was taken from Craig's standard reference book covering parliamentary elections in the 1970s (Craig, 1984). There are three potential candidates for the independent variable: the per cent of votes cast for the NF among those who went to the polls in February 1974, October 1974 and May 1979.

In contrast to Goodwin et al. who present a binary measure for "wards that are located within parliamentary constituencies where the BNP's main predecessor - the old NF - stood candidates at general elections during the 1970s', we use Max Goplerud's areal interpolation technique to estimate levels of past NF electoral support within

\footnotetext{
${ }^{5}$ Scotland has been excluded from the analysis due to unavailability of digital boundaries necessary to link the 1970 NF vote to the 2005 BNP vote. This should not affect the analysis in a significant way, since BNP voting, let alone NF voting has been negligible in Scotland.
} 
current parliamentary constituencies ${ }^{6}(2016)$. The method does not assume uniform distribution of the variables of interest and takes into account the varying population density at the constituency level. Thus, we are not limited to using binary variables but can introduce more exact measures of past time support. This is important, because areas where the NF polled almost 7 per cent of the vote in the 1970s are arguably different from places where it received a modest score of less than 0.5 per cent of the vote because the former had much larger demand for extreme right politics and this should be accounted for in the model. Table 1 provides descriptive statistics for general elections in the 1970s. The growing popularity of the NF was associated with discontent over immigration combined with negative portrayals of immigrants by some influential media outlets (consider the reaction to the arrival of Ugandan Asian refugees in 1972). As most extreme right parties, it performed better in second order elections (and by-elections) but that year it polled 9.4 per cent of votes in one constituency and an average of 3.1 per cent in constituencies where it stood candidates, arguably the best result for the party in a general election (Ford and Goodwin 2009). By the late 1970s the political landscape had shifted. The Conservative Party moved to the right on immigration and race relations, putting an end to the inflow of conservative supporters to the NF. The party also faced backlash over incitement of racial violence and was torn by internal leadership conflict. Although the NF contested the highest number of constituencies in 1979 by that time the party was in electoral decline and disintegrating (Copsey 2004). That year its candidates averaged just 1.3 per cent of the vote, a decline of almost two percentage points from what they polled in October 1974. For this reason we select the October 1974 election as the most accurate reflection of the support for the NF support at its peak.

\section{TABLE 1. Descriptive statistics for dependent and independent variables}

[Table 1 about here]

Jackman and Volpert argued that electoral success of extreme right parties should be

\footnotetext{
${ }^{6}$ This method allows projecting data across boundary changes. Apart from information about old and new boundaries and data to be interpolated it also requires population densities of smaller, underlying units (such as the Output Areas).
} 
modelled as left-censored at zero (1996). To address this problem we use Tobit regression that utilizes a maximum likelihood estimator for left-censored variables. A similar argument applies to the NF vote and we include a binary variable for constituencies where the party had no votes. This is because constituencies with no extreme right candidate may have some residual level of support, yet this potential cannot be turned into votes due to a lack of an appropriate candidate. This means that in constituencies where the party gets no votes the level of support for the extreme right is likely to be underestimated. The variable for no NF candidate is expected to be weakly positive.

\section{RESULTS}

Figure 1 reveals a weak positive correlation between the BNP and the NF vote. Note two distinctive clusters that seem to be jointly responsible for the overall low correlation $(r=0.08)$. One consists of predominantly urban constituencies such as Tottenham, East Ham, Leicester East or Hackney South and Shoreditch with strong support for the NF but no BNP vote; the other consists of small town and rural constituencies such as Dewsbury, Burnley or Dudley North where the BNP polled highly but with no record of NF voting in the past. This confirms what we already know about these two parties: the BNP was successful in small towns and rural areas while the NF could be descried as essentially an urban phenomenon.

\section{FIGURE 1. Extreme right vote in the 1970s and 2000s}

[Figure 1 about here]

Regressions results are presented in Table 1. We introduce a squared term to account for the existence of two distinct clusters. The NF vote does not reach statistical significance when it is regressed on its own together with a squared term and a binary variable for no candidate standing (Model 1). As expected the variable for no NF candidate standing is a positive predictor of the dependent variable, suggesting some residual level of previously untapped support. The results are similar when we introduce control variables (Model 2) that follow a pattern described in the literature, 
with higher educational attainment associated with lower levels of support for extreme right ${ }^{7}$. House ownership and council housing are positively associated with the BNP vote, although the coefficient for the share of residents in council housing is larger. Finally the share of non-whites has a positive coefficient but we cannot reject the null hypothesis of the coefficient being not statistically different from zero. Overall, Model 1 and 2 give no support for demand-side legacy effect for extreme right support. We can go one step further and see what happens if we use binary variables instead of more exact measure of electoral support. When we run a similar regression with binary variables (Model 3 and 4), our results are similar to those reported by Goodwin et al. for the supply-side legacy effect. We find that BNP voting is associated with extreme right voting in the past. Presence of the NF candidate remains a significant predictor of the dependent variable even when we control for other socio-economic variables.

TABLE 2. Tobit regression for the per cent of BNP vote in 2005 general election

\section{TABLE 3. Tobit regression for the per cent of BNP vote in 2005 general election (Cont.)}

[Table 2 and Table 3 about here]

\section{DISCUSSION}

In this study we have examined the association between historical and contemporary voting for two most successful extreme right parties in England and Wales. Before discussing the implications of this analysis, let us highlight its limitations. This study presents analysis at the aggregate level. We argue that this should not be a problem for detecting potential significance for the legacy effect because Goodwin and colleagues measured their legacy effect of supply de facto at an even larger level of the local authority. Our main variable was measured as the percentage of the total

\footnotetext{
${ }^{7}$ Share of residents in routine and semi-routine occupations (class 5 of NS-SEC occupational scale) is highly correlated with share of residents with no educational qualifications, so we decided against including both variables.
} 
vote instead of the percentage of the vote among white adults. Over the last 30 years the ethnic composition of some constituencies, notably those located in London, has changed significantly and this could explain to some extent why areas such as East Ham are no longer showing support for extreme right politics. Unfortunately, ethnic composition of constituencies in the 1970s is difficult to estimate.

Out results do not support the demand-side legacy effect. In fact we can see that historical strongholds have different profile from the contemporary ones. Importantly, our analysis also points to the benefit of using areal interpolation techniques to overcome the problem of changing electoral boundaries, which are a common obstacle in studies that seek to incorporate data from multiple elections. Although geographers have known these techniques for a while, there are now a number of tools that make these techniques accessible for a wider audience and easy to implement. If we had no access to more exact measures of electoral support and used binary variables instead, we would see a significant association between historical and contemporary extreme right voting. Using binary variables in this case would tap more into organizational factors (i.e. where the party had an operating unit and could stand candidates for general elections) than electoral support per se.

There remains one provocative question. Looking at Figure 1 one cannot help noticing that some of the constituencies that supported the NF in the 1970s had barely any BNP voters in 2005. What happened to people who resided in those extreme right urban strongholds thirty years later? This remains an open question. The ethnic composition of constituencies changed significantly and perhaps, if we believe that contact with minority groups reduces prejudice, those angry white men grew into politically moderate retirees. Another possibility assumes geographical mobility of $\mathrm{NF}$ voters, however one has to remember that in the British context the white flight hypothesis has to be taken with a dose of scepticism. Recently Kaufmann and Harris (2015) have shown that while it is true that white movers generally select whiter destinations than ethnic minorities, there is little difference in diversity of the destinations of those who tend to be pro-immigration (i.e. left leaning wit a degree) and those who are usually against it (declaring English identity). In another study Gallego, Buscha, Sturgis, and Oberski have shown that sorting of politically like- 
minded individuals into areas arises because people with different political preferences have different socio-economic characteristics (2014).

Overall, our findings are different from those reported by Goodwin et al. with respect to the supply-side legacy effect. Goodwin and colleagues argued that earlier cycles of activism contributed to exclusionary local climates that later facilitated the emergence of the BNP, here the main issue is whether there is evidence of local demand for extreme right politics expressed at the ballot box. Overall, while the legacy effect mechanisms proposed by Goodwin and colleagues seem to explain something about networks and continuities of activism they do not explain relations among voting publics over time.

\section{REFERENCES}

Biggs M and Knauss S (2012) Explaining Membership in the British National Party: A Multilevel Analysis of Contact and Threat. European Sociological Review 28 (5): 63346.

Craig FWS (1984). British parliamentary election results 1974-1983. Chichester: Parliamentary Research Services.

Eatwell R (2003) Ten theories of the extreme right. In: Merkl P and Weinberg L (eds) Right-Wing Extremism in the Twenty-first Century. London: Frank Cass, pp. 45-70.

Ford R and Goodwin MJ (2009) Something rotten in the heartlands? Ethnic competition, working class disaffection and the BNP challenge. Democracy, Citizens and Elections Research Network (DCERN) working paper series.

Ford R and Goodwin MJ (2010) Angry White Men: Individual and Contextual Predictors of Support for the British National Party. Political Studies 58 (1): 1-25.

Ford R and Goodwin MJ (2014) Revolt on the right: Explaining support for the radical right in Britain. London: Routledge.

Goodwin MJ (2011) New British Fascism: Rise of the British National Party. London: Routledge. 
Goodwin MJ, Ford R and Cutts D (2013) Extreme Right Foot Soldiers, Legacy Effects and Deprivation A Contextual Analysis of the Leaked British National Party (BNP) Membership List. Party Politics 19 (6): 887-906.

Goplerud M (2016) Crossing the Boundaries: An Implementation of Two Methods for Projecting Data across Boundary Changes. Political Analysis 24(1): 121-129.

Harrop M England J and Husbands CT (1980) The Bases of National Front Support. Political Studies 28 (2): 271-83.

Husbands CT (1983) Racial Exclusionism and the City: The Urban Support of the National Front. London: George Allen and Unwin.

Jackman R and Volpert K (1996) Conditions Favouring Parties of the Extreme Right in Western Europe. British Journal of Political Science 26(4), 501-521.

Kaufmann and Harris G (2015) "White Flight" or positive contact? Local diversity and attitudes to immigration in Britain. Comparative Political Studies 48(12): 1563-1590.

Morrow D (2000) Jörg Haider and the new FPÖ: beyond the democratic pale? In: Hainsworth P (ed) The Politics of the Extreme Right. London: Pinter, pp. 33-63.

Mudde C (2007) Populist radical right parties in Europe. Cambridge: Cambridge University Press.

Whiteley P (1979) The National Front Vote in the 1977 GLC Elections: An Aggregative Data Analysis. British Journal of Political Science 9(3): 370-380. 


\begin{tabular}{lccccr}
\hline Variable & Minimum & Maximum & Mean & S.D & $\mathrm{r}$ \\
\hline Dependent Variable & & & & & \\
BNP May 2005 & 0 & 17 & 0.89 & 2.07 & 1.00 \\
Independent Variables & & & & & \\
NF February 1974 & 0 & 7.73 & 0.27 & 0.90 & 0.06 \\
NF October 1974 & 0 & 7.54 & 0.43 & 1.08 & 0.08 \\
NF May 1979 & 0 & 6.60 & 0.70 & 0.89 & 0.12 \\
\hline $\mathrm{N}=569$ & & & & &
\end{tabular}

TABLE 1. Descriptive statistics for dependent and independent variables

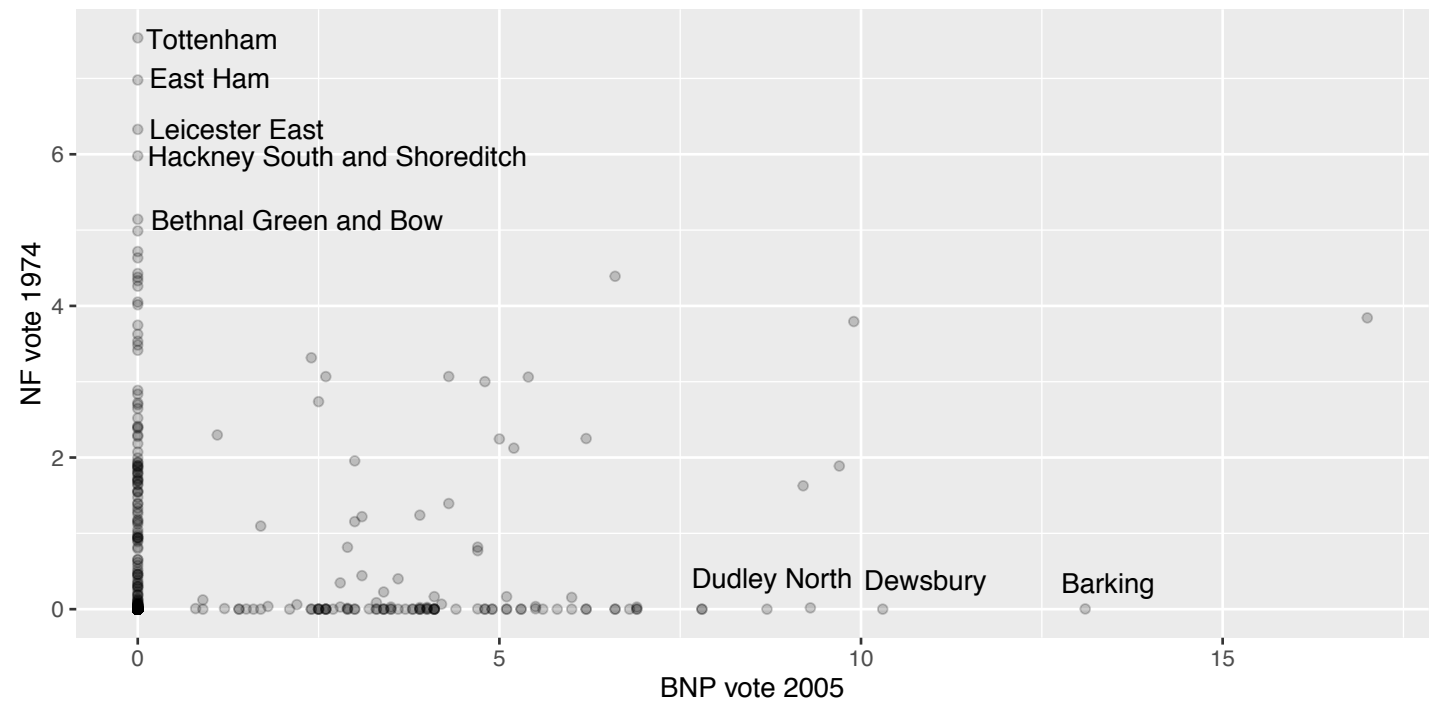

FIGURE 1. Extreme right vote in the 1970s and 2000s 


\begin{tabular}{|c|c|c|c|c|c|c|c|c|}
\hline \multirow{2}{*}{ Tobit regression } & \multicolumn{3}{|c|}{ Model 1} & \multicolumn{5}{|c|}{ Model 2} \\
\hline & Coeff. & S.E & P-value & & Coeff. & S.E & P-value & \\
\hline NF vote & 0.87 & 1.06 & 0.410 & & 0.57 & 0.94 & 0.548 & \\
\hline NF vote squared & -0.24 & 0.24 & 0.330 & & -0.29 & 0.23 & 0.204 & \\
\hline No candidate standing & 2.04 & 0.94 & 0.030 & $*$ & 2.65 & 0.82 & 0.001 & $* *$ \\
\hline Class: semi-routine/routine & & & & & 20.98 & 14.04 & 0.136 & \\
\hline Education: degree & & & & & -36.96 & 10.90 & 0.001 & $* *$ \\
\hline Non-white & & & & & 8.29 & 4.53 & 0.068 & \\
\hline Tenure: owned & & & & & 29.10 & 7.36 & 0.000 & $* * *$ \\
\hline Tenure: council & & & & & 33.62 & 7.57 & 0.000 & $* * *$ \\
\hline Density & & & & & 0.03 & 0.03 & 0.377 & \\
\hline Wales & & & & & -4.80 & 1.86 & 0.010 & $*$ \\
\hline Constant & -6.50 & 0.82 & 0.000 & $* * *$ & -29.23 & 8.58 & 0.001 & $* *$ \\
\hline Log likelihood & & -563.08 & & & & -487.80 & & \\
\hline Pseudo R squared & & 0.008 & & & & 0.141 & & \\
\hline Left-censored & & 117 & & & & 117 & & \\
\hline Uncensored & & 452 & & & & 452 & & \\
\hline
\end{tabular}

$\mathrm{N}=569$

$* * * \mathrm{p}<.001,{ }^{* *} \mathrm{p}<.01, * \mathrm{p}<.05$

TABLE 2. Tobit regression for the per cent of BNP vote in 2005 general election

\begin{tabular}{|c|c|c|c|c|c|c|c|c|}
\hline \multirow[t]{2}{*}{ Tobit regression } & \multicolumn{3}{|c|}{ Model 3} & \multicolumn{5}{|c|}{ Model 4} \\
\hline & Coeff. & S.E & P-value & & Coeff. & S.E & P-value & \\
\hline NF dummy & 2.24 & 0.80 & 0.005 & * & 2.63 & 0.73 & 0.000 & $* * *$ \\
\hline Class: semi-routine/routine & & & & & 17.49 & 13.97 & 0.211 & \\
\hline Education: degree & & & & & -38.60 & 10.97 & 0.000 & $* * *$ \\
\hline Non-white & & & & & 5.13 & 4.28 & 0.231 & \\
\hline Tenure: owned & & & & & 28.24 & 7.33 & 0.000 & *** \\
\hline Tenure: council & & & & & 32.43 & 7.51 & 0.000 & $* * *$ \\
\hline Density & & & & & 0.03 & 0.03 & 0.355 & \\
\hline Wales & & & & & -4.82 & 1.86 & 0.010 & * \\
\hline Constant & -6.51 & 0.82 & 0.000 & $* * *$ & -27.31 & 8.52 & 0.001 & $* *$ \\
\hline Log likelihood & & -563.68 & & & & -489.90 & & \\
\hline Pseudo R squared & & 0.01 & & & & 0.14 & & \\
\hline Left-censored & & 117.00 & & & & 117.00 & & \\
\hline Uncensored & & 452.00 & & & & 452.00 & & \\
\hline
\end{tabular}

TABLE 3. Tobit regression for the per cent of BNP vote in 2005 general election (Cont.) 